\title{
A New Type of Energy-Saving Extreme-Speed Fault Current Limiter
}

\author{
Xian Wang ${ }^{1, a}$ Lijun Qin ${ }^{1, b}$, Zhuofan Tang ${ }^{1, c}$ and Jun Liang ${ }^{2, d}$ \\ ${ }^{1}$ School of Electrical and Electronic Engineering, North China Electric Power University, Beijing \\ 102206, China; \\ ²Bazhou Power Supply Company, State Grid Corporation of China, Xinjiang 841000, China. \\ astillalice10@163.com, bqinlj@126.com, ctangvera@126.com, d820515425@qq.com
}

Keywords: Modularization, energy conservation, fault current limiting device, topology.

\begin{abstract}
In the practical application of power system fault protection, the traditional series current-limiting reactor has power loss and affects network security and stability. In order to exclude the negative impact, high-speed switch can be connected in parallel at both ends of the reactor. In that it can improve system short circuit maintenance, extend equipment life and improve operational reliability. The existing set of devices can only be installed on the series current limiting reactor line for the overall replacement, the project is complex and costly. A novel modular energy-saving fault current limiting device without removing the original series current-limiting reactor is proposed, which is simple in topology, economical in installation cost and suitable for wide application.
\end{abstract}

\section{Introduction}

With the development of power system in our country, the small capacity power supply is gradually integrated into the large power grid, the regional power grid interconnection is becoming more and more closely, the scale of the power system is expanded, and the load of the power system is growing rapidly. The power grid transmission capacity increased significantly, followed by the short-circuit current level is increasing, on the one hand it will increase the impact of the main equipment, easy to damage caused by accidents, security risks and economic losses, on the other hand, the short-circuit current level continues to rise, close to even exceed circuit breaker interrupting capacity, seriously affect the reliability of circuit breaker, has great harm [1-2].

The fault current limiting device is one of the main technical measures to effectively limit the short circuit current. The traditional current limiting reactor is connected in series in the transmission line, whose function is to make the short-circuit current not exceed the upper limit when the fault occurs, and to keep the bus voltage at $60 \% \sim 70 \%$, so as to ensure the reliability of the circuit breaker. This protection can only play a role in the short circuit occurs, in other cases there are some negative effects. (1) the current limiting reactor consumes electric energy. The reactor will produce a large pressure drop after the start-up of large equipment, which will affect the safety of the network. The reactor will produce a large pressure drop after the start-up of large equipment, which will affect the safety of the network. (3)a strong magnetic field is formed in the reactor, and a circulation is formed in the enclosed metal conductor in the inner and the periphery of the building. (4)Because of the series reactor will form the voltage drop, it is necessary to raise the voltage at the end of the generator and reduce the service life of the generator [3]. In paper [4], the topology of energy saving fault current limiter based on fast switching is introduced, and the simulation analysis is carried out. The intelligent high-speed switch is used as a converter, and is connected with a series current limiting reactor in parallel. In normal operation, the high speed switch is closed, the current only flows through the converter, the impedance is zero, and the power loss is zero. When the short circuit fault occurs, the high speed switch moves rapidly, and the converter branch is cut off so as to protect the current limiting reactor access system. In paper [5], a current limiting device for $220 \mathrm{Kv}$ and below voltage level is proposed, which can not only meet the need of limiting current, but also has a significant energy saving effect. The device has been put into operation in $35 \mathrm{Kv}$ power grid, and the disadvantage is that it cannot be 
reused. Based on the technology of fast vacuum circuit breaker, the rapid identification of short circuit current and the phase control technology, a set of $10 \mathrm{Kv}$ lossless current limiting device is developed, which can be used repeatedly after the circuit breaker is not changed.

At present, the effect of the current limiting device based on the large capacity high speed switch and current limiting reactor has been fully simulated and verified by the network operation. In practical application, the existing scheme needs to install a whole set of fault current limiting devices, and cannot be installed on the intelligent switch. The project is complex, time-consuming, high cost, and the solution is not flexible, and is not suitable for most of the grid connected current limiting reactors. To solve this problem, this paper designs a new type of modular energy-saving speed fault current limiting device, which has simple structure and can be quickly installed without replacing the original series current limiting reactor in the line, besides the cost is saved

\section{Technical Principle of Fault Current Limiter}

\subsection{Operating Principle of Fault Current Limiter.}

The fault current limiter is composed of a fast fault current detecting element, a fast switching switch, a current limiting reactor and an overvoltage protection element, as shown in figure 1[7].

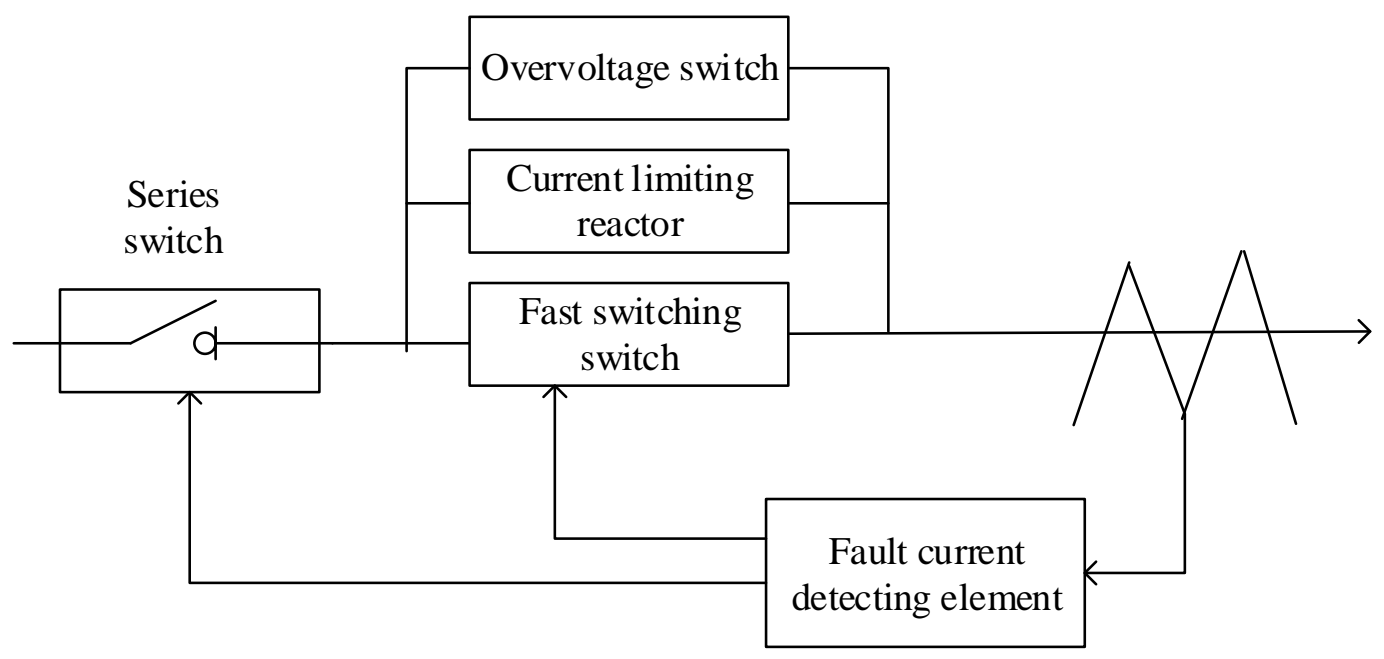

Fig. 1 Principle of fault current limiter

The model of fault current limiter described in this paper can be abstracted as shown in figure 2. In the figure, the $\mathrm{L}$ series current limiting reactor, $\mathrm{K}$ for intelligent speed switch, $\mathrm{ZnO}$ for Zinc Oxide over-voltage protection device, both ends for the device interface.

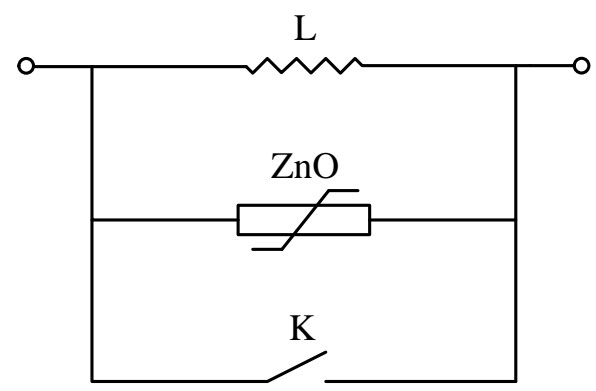

Fig. 2 Topology structure of fault current limiter

In normal operation, the intelligent switch is in the closed state, the operating current in the system only flows through the intelligent switch branch, and the impedance is zero, which can be assumed as no power loss. When a short circuit fault occurs, the intelligent switch is switched off in less than $10 \mathrm{~ms}$ and the current limiting reactor is put into the circuit, the device enters the current limiting working state, and the short circuit current is limited to the limit value where the circuit breaker can be switched. The $\mathrm{ZnO}$ device acts as an overvoltage protection. 


\subsection{Fast Vacuum Circuit Breaker.}

When short circuit fault occurs, the current limiting reactor is needed to be put into the loop, which depends on the rapid action of the smart switch. The research shows that the intelligent high-speed vacuum circuit breaker based on the eddy current drive technology can control the time of the gate to be less than $5 \mathrm{~ms}$. After a rigorous test, the steady-state recovery voltage of the $10 \mathrm{Kv}$ vacuum circuit breaker in the process of parallel current limiting reactor has reached more than $21 \mathrm{Kv}[6]$.

\subsection{Overvoltage Protection of Reactor.}

Overvoltage protection device uses Zinc Oxide varistor as reactor. Under normal operating voltage, the Zinc Oxide varistor has a high resistance state and a small leakage current. In the case of the surge overvoltage, the varistor becomes a low resistance state, and the current flowing through the Zinc Oxide overvoltage protection device is increased. Surge overvoltage is suppressed to protect the reactor. After the line voltage is normal, the varistor changes back to the high resistance state to maintain the normal operation of the circuit [8].

\section{Design of Modular Energy Saving Fault Current Limiter}

\subsection{Current Situation and Existing Problems.}

The purpose of setting the fault current limiting device is to control the short circuit current and protect the circuit when the system is short circuited. At present, the series current limiting reactor has been installed as the current limiting device. This series of reactors under long-term operation, consume a lot of energy, bringing potential security risks, needed to be upgrade. After the upgrade, the current limiting device adopts the parallel operation of intelligent switch and current limiting reactor. Because the fault current limiting device is a complete set of equipment, it is necessary to remove and replace the original reactor when it is applied to the circuit of the series reactor. The reconstruction project will affect the normal operation of the system, which is time-consuming and not suitable for a wide range of applications. With the development of fault current limiting device technology, coordination, cohesion in the fault current limiter with current limiting device and the protection of the conventional relay, and the installation cost and economic security problems gradually get attention.

\subsection{Solution}

In order to solve the problem that the fault current limiting device cannot meet the user's needs flexibly, considering the protection and utilization of the current limited reactor in the line, this paper presents a new type of modular energy saving fault current limiting device, and the topology is shown in Figure 3. Compared with the traditional fault current limiting device shown in Figure 2, the device is lack of current limiting reactor, only composed of intelligent speed switch and Zinc Oxide components.

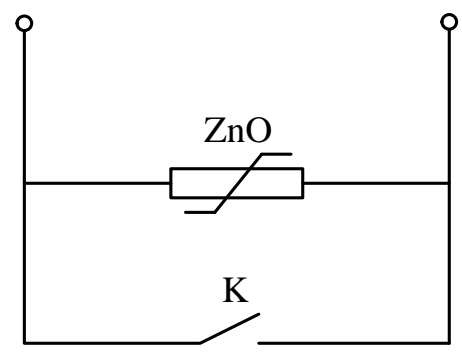

Fig. 3 Topology structure of modular fault current limiter

\subsection{Integrated Design of Modular Fault Current Limiter}

In this paper, the overall structure of the new modular energy-saving fault current limiter is shown in Figure 4, in which the dotted line is a modular device. 


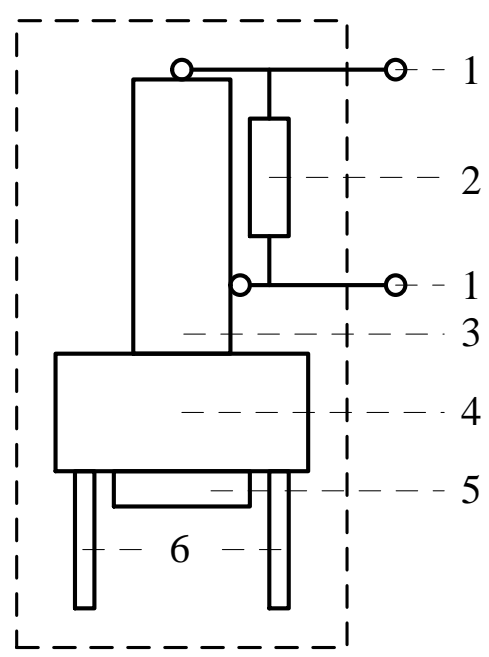

Fig. 4 Integral structure of modular fault current limiter

The main components and functions of the device are as follows.

1. Module interface: used to connect the original line current limiting reactor.

2. Zinc Oxide components: protection against overvoltage.

3. Vacuum interrupter: quickly extinguish the arc and suppress the current after cutting off the power supply.

4. Intelligent speed switch main body: intelligent speed switch for high speed operation.

5. Control module: the control system of the intelligent switch, complete the fault judgment and send out the action instruction.

6. Device support.

The device is connected with the current limiting reactor through a modular device interface on basis of the original current limited reactor of the line to form a complete set of fault current limiting device. The new modular fault current limiting device can be installed separately and be individually purchased without changing the original line current limiting reactor. The utility model not only has the advantages of low energy consumption and high operating speed as same as the energy saving type speed limiting device, but also can achieve the purpose of saving the cost of the capital.

\section{Application analysis of modular fault current limiter}

\subsection{Energy Saving Analysis}

When the fault current limiting device is not installed, the current limiting reactor generates energy consumption in the whole year. With reference to paper [3], a thermal power plant with three sets of steam turbines (two for $30 \mathrm{MW}$, one for $15 \mathrm{MW}$ ) as an example. The current limiting reactor (2500A, $2500 \mathrm{~A}, 1500 \mathrm{~A}$ ) is connected in series to the generator transmission line. According to the formula of $\mathrm{U}$ $*$ I * cos, it can be calculated that monthly energy consumption of three reactors is about $327348 \mathrm{kWh}$. When the fault current limiting device is installed, the reactor has no current flowing in the normal operation, and the energy consumption is almost zero. Only considering the energy consumption of the reactor, the three modular fault current limiting devices can save about 4 million kWh per year. The energy saving effect is obvious.

\subsection{Economic Benefit Analysis}

According to 2016 Inner Mongolia industrial electricity price $(0.54$ yuan $/ \mathrm{kWh})$, three reactors monthly electricity charges of about $327348 * 0.54=17.68$ million, which means that only reactor power consumption has been more than 2 million yuan, exceeding the purchase and installation costs of modular fault current limiting device. Based on the above analysis, the investment cost of equipment transformation can be recovered within one year.

\subsection{Safety Analysis}

The voltage of the bus will be affected by the reactor, and the voltage drop will cause the voltage fluctuation of the bus. When the fault current limiting device is installed, the reactor is short connected 
to the circuit under normal conditions, which improve voltage quality. In addition, it will eliminate the electromagnetic interference caused by the reactor, so as to avoid the eddy current of auxiliary equipment and two equipment discharge ignition, reduce security risks.

\section{Conclusion}

The design of modular fault current limiting device not only has the advantages of quick action, energy saving and consumption reduction, but also has the flexibility to adapt to the requirements of users. In addition, the project is simple and cost saving. In view of the problem of the transformation and upgrading of the current limited reactor in the power grid, modular fault current limiting device has wide application value.

\section{References}

[1]. Shumin Sun, Hongshun Liu, Qingmin Li, et al. Review of Fault Current Limiter in Power System [J]. Grid Technology. Vol. 32 (2008) No. 21, p. 75-79.

[2]. Ming Li, Xiaoqing Zhang. Research on Fault Current Limiter of Power System [J]. Electric Age (2005) No. 4, p. 54-56.

[3]. Jianlin Huang, Application Research on Parallel Operation of Large Capacity High Speed Switch and Current Limiting Reactor in Power Engineering [J]. Low Carbon World (2005) No. 12, p. 22-23.

[4]. Gang Wu, Guoyan Zhang, Jianmin Zhang, et al. Energy Saving Fault Current Limiter Based on Fast Switch [J]. Electrical Technology (2016) No. 1, p. 94-96.

[5]. Yongning Huang, Yiping Fan. Development and Application of Energy Saving Power Grid Current Limiting Device [J]. Ningxia Electric Power (2010), p. 37-41.

[6]. Changping an, Chunlei Wen, Shiyu Tang, et al. The Development and Test Run of 10Kv Switch Type Fault Current Limiter [J]. Journal of Chongqing Electric Power College. Vol. 18 (2013) No. 6, p. 34-37.

[7]. Kai Liu, Hongkun Chen, Jun Lin, et al. Application Status of Fault Current Limiter in Power System [J]. Power System Protection and Control. Vol. 38 (2010) No. 7, p. 147-151.

[8]. Qiusheng Jin. Overvoltage Protection of Zinc Oxide Varistor [J]. Public Electricity. (2004) No. 12, p. 35-36. 